Randomized Trial

\title{
E Implication of Two Different Doses of Intradiscal Ozone-Oxygen Injection upon the Pain Alleviation in Patients with Low Back Pain: A Randomized, Single-Blind Study
}

Abdelraheem Elawamy, MD1, Emad Zarief Kamel, MD1, Manal Hassanien, MD1, Ola M. Wahba, MD1, and Shereen Ezzat Amin, MD²

From: ${ }^{1}$ Assiut University, Assiut, Egypt; ${ }^{2}$ South Egypt Cancer Institute, Assiut University, Egypt

Address Correspondence: Emad Zarief Kamel, MD Department of Anesthesia and ICU Assiut University Assiut, Egypt

E-mail: emadzarief@yahoo.com

Disclaimer: There was no external funding in the preparation of this manuscript. Conflict of interest: Each author

certifies that he or she, or a member of his or her immediate

family, has no commercial association (i.e., consultancies, stock ownership, equity interest, patent/licensing arrangements, etc.) that might pose a conflict of interest in connection with the submitted manuscript.

Manuscript received: 01-19-2017 Revised manuscript received: 07-08-2017 Accepted for publication: 07-18-2017

Free full manuscript: www.painphysicianjournal.com
Background: Low back pain (LBP) is mostly induced by disc herniation (DH) or degeneration and has a burden upon social activity and economical aspects of life. An abundance of medical and surgical interventions have evolved to resolve this problem, but one of the newly introduced techniques, which is the minimally invasive, low cost ozone-oxygen mixture $\left(\mathrm{O}_{3}-\mathrm{O}_{2}\right)$ intradiscal injection, offers a rapid onset amelioration of symptoms with a sustained duration of pain relief.

Objective: We aim to evaluate the quality of pain alleviation using 2 different doses of intradiscal injections of $\mathrm{O}_{3}-\mathrm{O}_{2}$ mixture.

Study Design: A prospectively randomized, single-blind study.

Setting: Pain clinic, anesthesia, intensive care, and pain department in Assiut University Hospitals.

Methods: Sixty patients with symptomatizing single lumbar $\mathrm{DH}$ were subjected to $\mathrm{O}_{3}-\mathrm{O}_{2}$ intradiscal injection and randomly allocated into one of 2 groups; group A: received $10 \mathrm{~mL}, 40 \mu \mathrm{g} /$ $\mathrm{mL}$ of $\mathrm{O}_{3}-\mathrm{O}_{2}$ and group $\mathrm{B}$ : received $10 \mathrm{~mL}, 30 \mu \mathrm{g} / \mathrm{mL}$ of $\mathrm{O}_{3}-\mathrm{O}_{2}$. Pain score and functional ability of the patients using the visual analog scale (VAS) and Oswestry Disability Index (ODI) were evaluated after 1, 6, and 12 months and compared to the basal values. Patient satisfaction and reduction of $\mathrm{DH}$ were evaluated after the sixth month.

Results: There were no significant differences between the 2 groups regarding the clinical outcome; however both the ODI and VAS evaluations showed highly significant improvement (decreased) $(P<0.01)$ after injection and during the entire follow-up period. There were highly significant negative correlations between the $\mathrm{DH}$ reduction percentage and both the VAS and ODI scores after 6 months in both of the groups.

Limitations: This study was limited by a small sample size; it was also an active control trial, which may explain the insignificant difference in between the groups, in addition to being a singleblind trial.

Conclusion: Intradiscal injection of $\mathrm{O}_{3}-\mathrm{O}_{2}$ mixture is a very valuable maneuver in the reduction of DH size and improvement of pain quality, with either ozone concentrations of $40 \mu \mathrm{g} / \mathrm{mL}$ or 30 $\mu \mathrm{g} / \mathrm{mL}$.

Key words: Low back pain, ozone, disc herniation

Clinical Trial Number and Registry: The protocol local registration number is IRB00009908, in 2/08/2015, and the ClinicalTrials.gov identifier is NCT03023969.

Pain Physician 2018; 21:E25-E31 
hronic low back pain (LBP) is a very common problem affecting the quality of life nowadays. LBP is mostly induced by disc herniation (DH) or degeneration. DH and degeneration have mechanical, biochemical, and inflammatory burdens upon the nerve roots, endanger neurological integrity, and induce radicular pain $(1,2)$.

Patients with such conditions usually seek medical and/or surgical intervention (open, full endoscopic, or micro endoscopic discectomy) (3). Unfortunately, a recent research performed in 2014 noted that the rate of redo surgeries of such cases has increased to $10-25 \%$ (4).

In the same time, a lot of modalities of non-surgical interventions have emerged as other choices that may improve the outcome and decrease the patient's complaint. A good quality of pain alleviation was obtained by opioids in a study of 2,468 patients with LBP; the study recommended future prospective studies that could address the opioid use objectively in such group of patients (5). Physiotherapy use in some cases of LBP may offer some improvement, yet it did not shown significant benefit upon the pain quality in a study of 363 patients with LBP due to DH in 2016 (6).

Injections of local anesthetics and or long-acting steroids are attractive choices due to their decreased invasiveness, side effects, and cost (7). Recently, intradiscal injection of ozone-oxygen $\left(\mathrm{O}_{3}-\mathrm{O}_{2}\right)$ mixture just beyond the $\mathrm{DH}$ has been established in many countries, especially in Europe, as an alternative safe choice. Studies denoted that this mix offers a very significant amelioration of symptoms in a very short time-period, with sustained duration up to 1 year. $\mathrm{O}_{3}-\mathrm{O}_{2}$ mixture is readily available, and the technique is considered to be cheap, minimally invasive, and safe. The suspected mechanism of its efficacy is the shrinkage of the nucleus pulpous structure of the herniated disc, in addition to ozone's ability to block intraforaminal inflammation so that the pain intensity decreases (8-10).

In this study we aim to evaluate the quality of pain alleviation and hence functional ability improvement by using 2 different doses of intradiscal injections of $\mathrm{O}_{3}-\mathrm{O}_{2}$ mixture.

\section{Methods}

This study was approved by the local research ethics committee of the Faculty of Medicine, Assiut University in Egypt. It was conducted in Assiut University Hospitals, Pain Clinic, in accordance with the Consolidated Standards of Reporting Trials (Fig. 1) and is reg- istered with the following ClinicalTrials.gov identifier: NCT03023969.

Written informed consents were obtained from all of the patients, who were suffering from radicular leg pain and LBP, with the duration of symptoms varying from 1 to 6 months. This group of patients was nonresponsive to conservative treatment modalities, even partially, with visual analog scale (VAS) scores higher than 7. By magnetic resonance imaging (MRI), we identified the protruded or extruded disc between L1 and S1.

Exclusion criteria included patients who had infection near the suspected site of injection, any element of nerve palsy, sequestrated disc fragments in MRI, spinal pathologies such as tumors, lyses, fractures, or severe stenosis, and those who underwent previous spinal surgeries.

The patients were randomized using the sealed envelope method to receive the mixture in $10 \mathrm{~mL}$ volume with either concentration of $40 \mu \mathrm{g} / \mathrm{mL}$ of $\mathrm{O}_{3}-\mathrm{O}_{2}$ in group A or $30 \mu \mathrm{g} / \mathrm{mL}$ of $\mathrm{O}_{3}-\mathrm{O}_{2}$ in group $\mathrm{B}$. The pain assessment physician had no knowledge of which dose was given to each patient. We compared the alleviation of pain in both groups apart from their baseline values.

The procedure was performed in the operative room under moderate sedation with intravenous 1:2 $\mathrm{mg}$ midazolam. After standard local antiseptic preparation and sterile draping with the patient in the prone position, a Chiba-type needle (18 gauge, $27 \mathrm{~cm}$ long) was introduced by the standard posterolateral, extraarticular percutaneous approach. The side of approach corresponded to the side of DH as seen on the MR images. Anteroposterior and lateral imaging confirmed the position of the needle within the disc, and the needle-tip was situated centrally inside the nucleus pulposus, followed by the positioning of a bacteriological Millipore filter between the syringe and the needle before infiltrating the gas mixture inside the disc space. The $\mathrm{O}_{3}-\mathrm{O}_{2}$ mixture was produced in real-time by a medical ozone generator (Ozonline E80, Medical Srl, Bologna, Italy) and visibly released inside the disc space at an approximate 3-minute duration, showing dispersion through the space on fluoroscopy. The patients were discharged after 4 hours of observation.

Pain score and functional ability of the patients according to the Oswestry Disability Index (ODI) and VAS were recorded prior to the procedure and then after 1,6 , and 12 months. Patient satisfaction was assessed using the Likert scale; grade 1: the patient's satisfaction was $30 \%$, grade 2 : satisfaction was $30-50 \%$, grade 3 : 


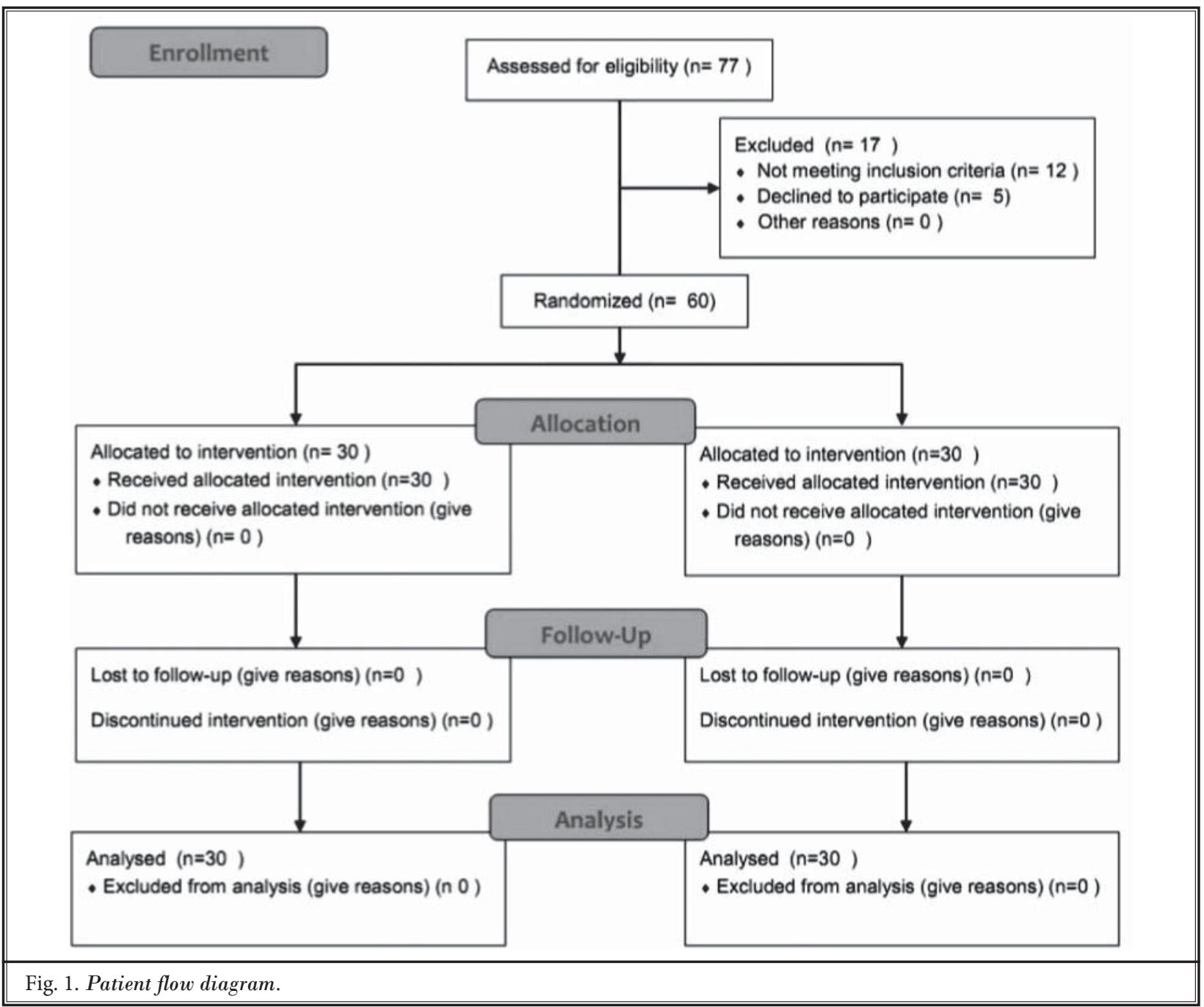

satisfaction was $50-80 \%$, and grade 4: satisfaction was above $80 \%$. Both grades 3 and 4 were defined as "overall satisfied." The reduction of $\mathrm{DH}$ size in percentage was recorded in axial and sagittal views of MRI after the sixth month, evaluated by a radiologist who was blind to the randomization, and was compared to the preinjection images. The evaluation of MRI was based upon Michigan State University (MSU) classification (11).

Any complication or the need for surgical intervention was recorded during the study period.

\section{Statistical Analysis}

We determined a sample size of 30 patients per group to obtain a study power of $80 \%$ to detect a difference at the significance level of $5 \%$. Data were expressed as mean, standard deviation (SD), or standard error (SE) numbers and percentages as appropriate. Categorical variables were analyzed using a chi-square $\left(\chi^{2}\right)$ test. Continuous variables were analyzed using an unpaired Student's t-test. Nominal and non-normally distributed variables were analyzed using the MannWhitney $U$ test. Pearson correlations between $\mathrm{DH}$ reduction and corresponding ODI, VAS, and patient's satisfaction evaluations were used. Statistical analysis was performed using SPSS Version 23.0 (IBM Corporation, Armonk, NY). A $P$ value $<0.05$ was considered statistically significant.

\section{Results}

A total of 60 patients were included in the study and randomly allocated to one of the 2 study groups. The patients' demographic data, percentages of $\mathrm{DH}$, 
and analgesia reductions are shown in Table 1, with insignificant differences in between both groups.

Pain evaluation results are shown in Table 2 and Fig. 2. Pre-procedure VAS $(0)$ scores were $8.3 \pm 0.18$ and $8.2 \pm 0.18$ in groups $A$ and $B$ respectively, with an insignificant difference between the 2 groups. The same regarding baseline ODI (0) values were $3.7 \pm 0.4$ in group $A$ and $3.8 \pm 3.66$ in group $B$, with an insignificant difference between the 2 groups. However, the post-intervention values of the VAS and ODI showed highly significant decreases in comparison to their basal values, starting from the first and sixth months and continued to decrease up to the twelfth month.

Patients satisfaction (Likert scale) for each group in correspondence to their baseline DH (using MSU

Table 1. Patients' demographic and clinical data.

\begin{tabular}{|c|c|c|c|c|}
\hline \multicolumn{2}{|c|}{ Characteristics } & $\begin{array}{l}\text { Group A } \\
(\mathbf{n}=\mathbf{3 0})\end{array}$ & $\begin{array}{l}\text { Group B } \\
(\mathbf{n}=\mathbf{3 0})\end{array}$ & $P$-value \\
\hline \multirow{2}{*}{ Gender } & Male & 16 & 11 & \multirow{2}{*}{0.19} \\
\hline & Female & 14 & 19 & \\
\hline \multicolumn{2}{|c|}{ Age (yrs) } & $40.7 \pm 10.7$ & $39.7 \pm 9.2$ & 0.72 \\
\hline \multicolumn{2}{|c|}{ BMI $\left(\mathrm{kg} / \mathrm{m}^{2}\right)$} & $28.6 \pm 5.5$ & $29.6 \pm 5$ & 0.38 \\
\hline \multicolumn{2}{|c|}{ DH reduction (\%) } & $53.76 \pm 25.26$ & $54.2 \pm 24.3$ & 0.95 \\
\hline \multicolumn{2}{|c|}{$\begin{array}{l}\text { Reduction } \\
\text { of analgesia } \\
\text { requirement (\%) }\end{array}$} & $66.3 \pm 15$ & $71.3 \pm 16$ & 0.62 \\
\hline
\end{tabular}

Data are expressed as mean \pm SD, numbers. BMI: body mass index; DH: disc herniation

$P>0.05$ was considered statistically non-significant.

Table 2. VAS and ODI scores for the patients in each group.

\begin{tabular}{|l|c|c|c||}
\hline \multicolumn{1}{|c|}{ Variables } & Group A & Group B & P-value \\
\hline \multicolumn{4}{|c||}{ VAS SCORE } \\
\hline VAS 0 baseline & $8.3 \pm 0.18$ & $8.2 \pm 0.18$ & 0.8 \\
\hline VAS 1st mo & $2.5 \pm 0.37^{* * *}$ & $2.3 \pm 0.36^{* * *}$ & 0.8 \\
\hline VAS 6th mo & $2.1 \pm 0.25^{* * *}$ & $1.8 \pm 0.27^{* * *}$ & 0.59 \\
\hline VAS 12th mo & $1.7 \pm 0.24^{* * *}$ & $1.76 \pm 0.24^{* * *}$ & 0.907 \\
\hline \multicolumn{4}{|c|}{ ODI SCORE } \\
\hline ODI 0 baseline & $3.7 \pm 0.08$ & $3.8 \pm 0.07$ & 0.42 \\
\hline ODI 1st mo & $1.5 \pm 0.16^{¥ ¥}$ & $1.4 \pm 0.14^{¥ ¥ *}$ & 0.51 \\
\hline ODI 6th mo & $1.22 \pm 0.08^{¥ ¥}$ & $1.26 \pm 0.08^{¥ ¥}$ & 0.76 \\
\hline ODI 12th mo & $1.2 \pm 0.07^{¥ ¥}$ & $1.2 \pm 0.07^{\text {¥¥ }}$ & 1 \\
\hline Patient satisfaction & $3.1 \pm 0.23$ & $2.96 \pm 0.23$ & 0.75 \\
\hline
\end{tabular}

Data are expressed as mean \pm SE. VAS: visual analog scale; ODI; Oswestry Disability Index.

$P>0.05$ was considered statistically non-significant.

${ }^{* * *}$ ) Very significant difference between VAS to baseline values.

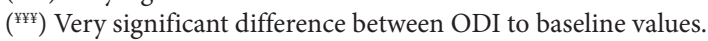

classification in MRI) showed insignificant differences between the 2 groups $(P=0.73)$, as shown in Table 3 .

There were highly significant negative correlations between the $\mathrm{DH}$ reduction percentage and the VAS score after the sixth month in both groups; Pearson's $r$ was -0.45 in group $A$ and -0.56 in group $B$. When $\mathrm{DH}$ reduction was correlated with the ODI questionnaire, in group A, Pearson's r was -0.445 versus -0.65 in group $B$, and both were highly significant. Patient's satisfaction showed significant positive correlations with $\mathrm{DH}$ reduction in both groups, with Pearson's $r$ values of 0.78 and 0.63 in groups A and B respectively (Figs. 3 and 4).

There was no recorded complication during the study period, and no patient sought surgical intervention within the 12 months.

\section{Discussion}

Intradiscal $\mathrm{O}_{3}-\mathrm{O}_{2}$ chemonucleolysis is a well-known and effective treatment for pain caused by protruding disc disease and nerve root compression due to bulging or herniated disc.

This study aimed to evaluate the effect of intradiscal injections of $\mathrm{O}_{3}-\mathrm{O}_{2}$ mixture on pain quality, and we found highly significant decreases of VAS scores, which started by the first month and continued during the study period. This can be linked to the mechanisms by which ozone relieves acute and chronic pain problems. Ozone has an oxidative conditioning effect upon many inflammatory mediators such as tumor necrosis factor alpha (TNF- $\alpha$ ), interleukin-1beta (IL-1 $\beta$ ), and other molecules, as well as its influence upon reactive oxygen species such as nitric oxide (NO) (12).

It was evidenced that the mixture of $\mathrm{O}_{3}-\mathrm{O}_{2}$ has dose-related effects. At "high" concentrations (40-70 $\mu \mathrm{g} \mathrm{O}_{3} / \mathrm{mL} \mathrm{O}_{2}$ ), it enhances alterations and destruction of tissue structures, at medium concentrations (20-30 $\mathrm{\mu g}$ $\left.\mathrm{O}_{3} / \mathrm{mL} \mathrm{O}_{2}\right)$, it appears to affect the regulation of the immune system, and at lower concentrations $\left(<20 \mu \mathrm{g} \mathrm{O}_{3} /\right.$ $\mathrm{mL} \mathrm{O}_{2}$ ), it improves microcirculation (13). We attempted to determine any significant difference between the 2 different ozone doses used, aiming to obtain the least dose with sustained pain relief effect, especially since many studies have used variable doses of $\mathrm{O}_{3}-\mathrm{O}_{2}$ mixture, e.g., $4 \mathrm{~mL}, 40 \mu \mathrm{g} / \mathrm{mL}$ (2), $4 \mathrm{~mL}, 27 \mu \mathrm{g} / \mathrm{mL}$ (14), and 15 $\mathrm{mL}, 20 \mu \mathrm{g} / \mathrm{mL}$ (15), and all of them showed significant improvement. However, recent preliminary results noticed ozone injection side effects in the form of hard adhesions between the bony and soft tissue structures when surgical intervention was used later on, and this highlights a recommended revision of ozone injection 


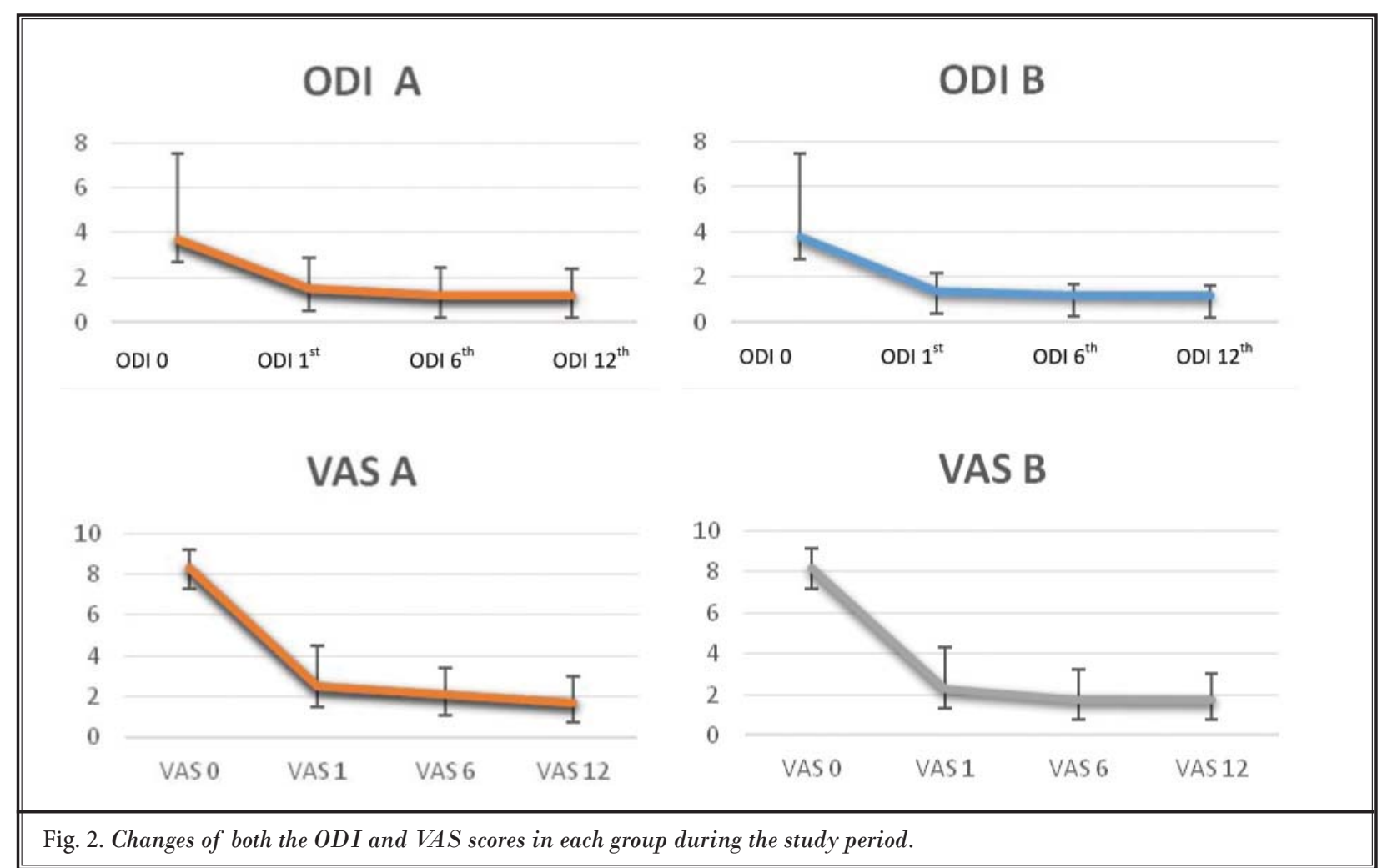

Table 3. Baseline DH grading and corresponding patient satisfaction by the 6th month in both of the groups.

\begin{tabular}{||l|c|c|c|c|c|c|c||}
\hline \hline MSU & \multicolumn{2}{|c|}{$\begin{array}{c}\text { Excellent/ } \\
\text { Good }\end{array}$} & \multicolumn{2}{|c|}{ Fair } & \multicolumn{2}{c||}{ Poor } & Total \\
\hline Groups & A & B & A & B & A & B & \\
\hline 1A & 3 & 2 & 0 & 0 & 0 & 0 & 5 \\
\hline 1C & 1 & 1 & 0 & 0 & 0 & 0 & 2 \\
\hline 2A & 2 & 2 & 0 & 0 & 0 & 0 & 4 \\
\hline 2B & 3 & 3 & 0 & 1 & 0 & 0 & 7 \\
\hline 2C & 0 & 1 & 2 & 0 & 1 & 0 & 4 \\
\hline 2AB & 3 & 3 & 2 & 2 & 0 & 1 & 11 \\
\hline 3A & 3 & 1 & 2 & 2 & 1 & 2 & 11 \\
\hline 3B & 2 & 2 & 0 & 3 & 1 & 0 & 8 \\
\hline 3AB & 2 & 1 & 1 & 1 & 1 & 2 & 8 \\
\hline Total & 19 & 16 & 7 & 9 & 4 & 5 & 60 \\
\hline \hline
\end{tabular}

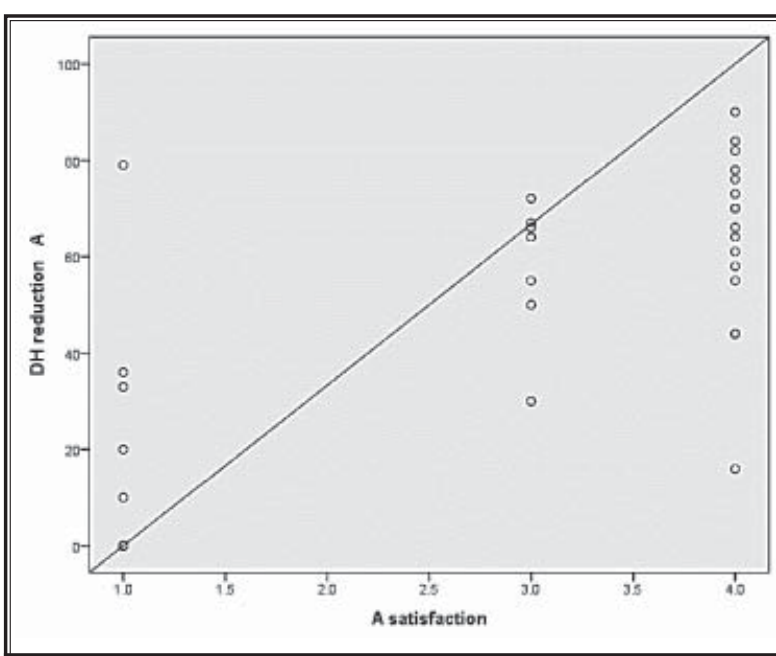

Fig. 3. Scattering the correlation between DH reduction and patient's satisfaction in group $A$.

we haven't found any significant difference in outcome between the 2 doses of $\mathrm{O}_{3}-\mathrm{O}_{2}$.

Some researchers studied local ozone injection for LBP in one group of patients and in one definite dose. In 2013, Magalhães et al (18) investigated the epidural injection of ozone upon a single group of 13 sequential 


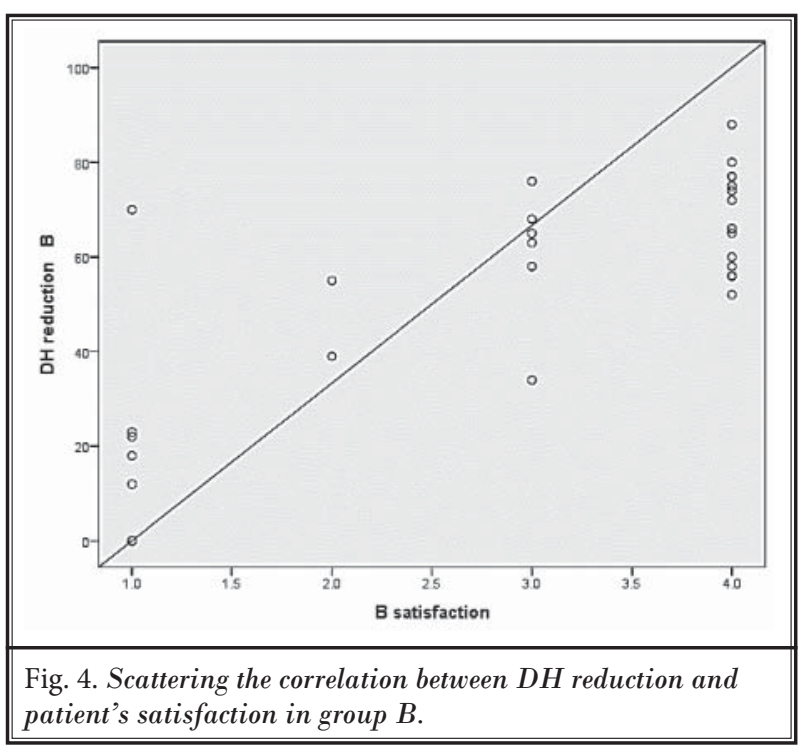

adult patients with chronic low lumbar pain after failed back surgery syndrome. The patients had a reduction of LBP by $43.7 \%$ in 6 months followed by $44.0 \%$ of improvement in the ODI. Another single group of 30 adult patients with LBP with DH underwent intradiscal injection of $\mathrm{O}_{3}-\mathrm{O}_{2}$ mixture $(4 \mathrm{~mL}, 40 \mu \mathrm{g} / \mathrm{mL})$; the study was done in 2014 by Hashemi et al (2) and a significant amelioration of pain and decrease of the ODI evaluation was noted.

The early improvement, which we found by the end of the first month in both groups, is in agreement with the study by Dall'Olio et al (14) of 13 continuative adult patients suffering from partial motor weakness and LBP due to lumbar DH who underwent percutaneous $\mathrm{O}_{3}-\mathrm{O}_{2}$ chemonucleolysis treatment under fluoroscopic guidance; the pain relief and motor improvement were noted early after 2 weeks.

In our study we have found a valuable reduction of $\mathrm{DH}$ by the sixth month, which significantly correlated with a reduction of VAS and ODI questionnaire scores. In 2016, Bonetti et al (19) demonstrated that even in longterm $\mathrm{DH}$, the ozone injection has the ability to reduce the disc size without any supplemental medications.

Some studies compared $\mathrm{O}_{3}-\mathrm{O}_{2}$ mixtures alone and with additives upon a series of cases of DH. In 2013, Zhang and his colleagues (20) compared the epidural usage of $\mathrm{O}_{3}-\mathrm{O}_{2}$ mixture and with steroids added to the same mixture in 2 groups of 172 patients with DH who failed to respond to conventional therapy and found excellent pain alleviation by nucleolysis in both of the groups with insignificant difference. They recommended that the use of $\mathrm{O}_{3}-\mathrm{O}_{2}$ could only be sufficient to reduce the disc size and alleviate the pain. They also recommended the use of ozone before recourse to surgical intervention or when surgery is not possible.

The patients varied in their clinical response to intradiscal ozone injection; therefore, its use has been called into a question in pain clinics, so it was important to evaluate treated discs with ozonolysis confirmed by MRI follow-up. We found highly significant correlations between the $\mathrm{DH}$ reduction percentage and the VAS, ODI, and patient's satisfaction evaluations after 6 months in both groups, and the DH size reduction was more than $50 \%$ in both groups; this can be interpreted by the nucleolysis mentioned by Zhang et al (20).

A comparison was done by Apuzzo et al (15) between $\mathrm{O}_{3}-\mathrm{O}_{2}$ therapy and global postural reeducation (GPR) in complicated chronic LBP reeducation or a combination of the $2\left(\mathrm{O}_{3}-\mathrm{O}_{2}+\mathrm{GPR}\right)$. Follow-up showed that pain severity was lower in the $\mathrm{O}_{3}-\mathrm{O}_{2}$ group than in the GPR-alone group. This study denoted that ozone alone can produce a sharp decrease of pain in short term, and the use of GPR could increase the duration of pain alleviation. In contrast to our study, they denoted that many cases which were injected with ozone showed no improvement, or even enlargement, of the $\mathrm{DH}$, with no difference in pain alleviation when compared with the other cases, which showed reduction of the $\mathrm{DH}$, suggesting that pain is not necessarily correlated to $\mathrm{DH}$ size.

There are a couple limitations to this study, the small sample size being one. It was also an active control trial, which may explain the insignificant difference in between the 2 groups; in addition to that, it was a single-blind trial .

No significant difference between the 2 doses of $\mathrm{O}_{3}-\mathrm{O}_{2}$ used in our study upon the pain alleviation quality or patient satisfaction was found. We did find that an $\mathrm{O}_{3}-\mathrm{O}_{2}$ mixture can offer rapid onset and sustained improvement of LBP.

\section{Author Contribution}

Dr. Emad Zarief and Dr. Abdelraheem Elawamy had full access to all the data in the study and take the responsibility for the integrity of the data and the accuracy of the data analysis. Dr. Shereen Ezzat and Dr. Ola Wahba designed the study protocol. Dr. Emad Zarief, Dr. Abdelraheem Elawamy, and Dr. Manal Hassanien managed the literature searches and summaries of the previous related work and wrote the first draft of the manuscript. 


\section{References}

1. Kaye AD, Manchikanti L, Abdi S, Atluri $\mathrm{S}$, Bakshi S, Benyamin R, Boswell MV, Buenaventura R, Candido KD, Cordner HJ, Datta S, Doulatram G, Gharibo CG, Grami V, Gupta S, Jha S, Kaplan ED, Malla Y, Mann DP, Nampiaparampil DE, Racz G, Raj P, Rana MV, Sharma $M L$, Singh V, Soin A, Staats PS, Vallejo R, Wargo BW, Hirsch JA. Efficacy of epidural injections in managing chronic spinal Pain: A best evidence synthesis. Pain Physician 2015; 18:E939-E1004 .

2. Hashemi M, Poorfarokh M, Mohajerani SA, Jalili P, Akhyani V, Barikani A, Farivar $\mathrm{F}$. Injection of intradiscal $\mathrm{O}_{2}-\mathrm{O}_{3}$ to reduce pain and disability of patients with low back pain due to prolapsed lumbar disk. Anesth Pain Med 2014; 4:e19206.

3. Phan K, Xu J, Schultz K, Alvi MA, Lu VM, Kerezoudis P, Maloney PR, Murphy ME, Mobbs RJ, Bydon M. Full-endoscopic versus micro-endoscopic and open discectomy: A systematic review and metaanalysis of outcomes and complications. Clin Neurol Neurosurg 2017; 154:1-12.

4. Buric J, Rigobello L, Hooper D. Five and ten year follow-up on intradiscal ozone injection for disc herniation. Int J Spine Surg 2014; 8; doi:10.14444/1017.

5. Chung SS, Park CK, Cho KJ, Choi KH, Kim JH, Kim SB, Kuh SU, Lee JC, Lee $J H$, Lee KY, Lee SH, Moon SH, Park SY, Shim JH, Son BC, Yoon MH, Park HJ. A nationwide retrospective study of opioid management patterns in 2,468 patients with spinal pain in Korea. Asian Spine ] 2016; 10:1122-1131.

6. Thackeray A, Fritz JM, Lurie JD, Zhao W, Weinstein JN. Nonsurgical treatment choices by individuals with lumbar intervertebral disc herniation in the United States: Associations with long-term outcomes. Am J Phys Med Rehabil 2017; 96:557-564.
7. Manchikanti L, Nampiaparampil DE, Manchikanti KN, Falco FJ, Singh V, Benyamin RM, Kaye AD, Sehgal N, Soin A, Simopoulos TT, Bakshi S, Gharibo CG, Gilligan CJ, Hirsch JA. Comparison of the efficacy of saline, local anesthetics, and steroids in epidural and facet joint injections for the management of spinal pain: A systematic review of randomized controlled trials. Surg Neurol Int 2015; 6:S194-S235.

8. Gautam S, Rastogi V, Jain A, Singh AP. Comparative evaluation of oxygenozone therapy and combined use of oxygen-ozone therapy with percutaneous intradiscal radiofrequency thermocoagulation for the treatment of lumbar disc herniation. Pain Pract 2011; 11:160-166.

9. Masini M, Calaça A. Minimally invasive treatment for refractory low back pain, targeted by epidural endoscopy with $\mathrm{O}_{2} /$ $\mathrm{O}_{3}$ and steroid therapy. Acta Neurochir Suppl 2011; 108:33-37.

10. Magalhaes FN, Dotta L, Sasse A, Teixera MJ, Fonoff ET. Ozone therapy as a treatment for low back pain secondary to herniated disc: A systematic review and meta-analysis of randomized controlled trials. Pain Physician 2012; 15:E115-E129.

11. Mysliwiec LW, Cholewicki J, Winkelpleck MD, Eis GP. MSU classification for herniated lumbar discs on MRI: Toward developing objective criteria for surgical selection. Eur Spine J 2010; 19:1087-1093.

12. Vaillant JD, Fraga A, Díaz MT, Mallok A, Viebahn-Hänsler R, Fahmy Z, Barberá A, Delgado L, Menéndez $S$, Fernández OS. Ozone oxidative postconditioning ameliorates joint damage and decreases proinflammatory cytokine levels and oxidative stress in PG/PS-induced arthritis in rats. Eur J Pharmacol 2013; 714:318-324.

13. Chang JD, Lu HS, Chang YF, Wang D. Ameliorative effect on ozone on cytokine production in mice injected with human rheumatoid arthritis synovial fibroblast cells. Rheumatol Int 2005; 26:141-151.

14. Dall'Olio M, Princiotta C, Cirillo L, Budai C, de Santis F, Bartolini S, Serchi E, Leonardi M. Oxygen-ozone therapy for herniated lumbar disc in patients with subacute partial motor weakness due to nerve root compression. Interv Neuroradiol 2014; 20:547-554.

15. Apuzzo D, Giotti C, Pasqualetti P, Ferrazza $P$, Soldati $P$, Zucco GM. An observational retrospective/horizontal study to compare oxygen-ozone therapy and/ or global postural re-education in complicated chronic low back pain. Funct Neurol 2014; 29:31-39.

16. Vanni D, Galzio R, Kazakova A, Pantalone A, Sparvieri A, Salini V, Magliani V. Intraforaminal ozone therapy and particular side effects: Preliminary results and early warning. Acta Neurochir (Wien) 2016; 158:491-496.

17. Al-Jaziri AA, Mahmoodi SM. Painkilling effect of ozone-oxygen injection on spine and joint osteoarthritis. Saudi Med J 2008; 29:553-557.

18. Magalhães FN, Soares SC, Torres JM, Ungaretti A, Cacciacarro MF, Teixeira MJ, Fonoff ET. Effects of ozone applied by spinal endoscopy in patients with chronic pain related to failed back surgery syndrome: A pilot study. Neuropsychiatr Dis Treat 2013; 9:1759-1766.

19. Bonetti $M$, Zambello A, Leonardi $M$, Princiotta C. Herniated disks unchanged over time: Size reduced after oxygen-ozone therapy. Interv Neuroradiol 2016; 22:466-472.

20. Zhang Y, Ma Y, Jiang J, Ding T, Wang J. Treatment of the lumbar disc herniation with intradiscal and intraforaminal injection of oxygen-ozone. J Back Musculoskelet Rehabil 2013; 26:317-322. 